\title{
BMJ
}

\section{Overnight closed loop insulin delivery (artificial pancreas) in adults with type 1 diabetes: crossover randomised controlled studies}

\author{
Roman Hovorka, principal research associate, ${ }^{1,2}$ Kavita Kumareswaran, clinical research fellow, ${ }^{1,3}$ Julie Harris, \\ research nurse, ${ }^{1}$ Janet M Allen, research nurse, ${ }^{1,2}$ Daniela Elleri, clinical research fellow, ${ }^{1,2}$ Dongyuan Xing, \\ biostatistician, ${ }^{4}$ Craig Kollman, senior biostatistician, ${ }^{4}$ Marianna Nodale, research assistant, ${ }^{1}$ Helen R Murphy, \\ senior research associate, ${ }^{1}$ David B Dunger, professor of paediatrics, ${ }^{1,2}$ Stephanie A Amiel, professor of \\ diabetic medicine, ${ }^{5}$ Simon R Heller, professor of diabetes, ${ }^{6}$ Malgorzata E Wilinska, research associate, ${ }^{1,2}$ Mark \\ L Evans, senior lecturer ${ }^{1,3}$
}

1 Institute of Metabolic Science, University of Cambridge, UK

${ }^{2}$ Department of Paediatrics, University of Cambridge, UK

${ }^{3}$ Department of Medicine University of Cambridge, UK

${ }^{4}$ The Jaeb Center for Health Research, Tampa, FL 33647, USA

${ }^{5}$ Diabetes Research, Weston Education Centre, King's College London, London, UK

${ }^{6}$ Diabetes Centre, Clinical Sciences Centre, Northern General Hospital, Sheffield, UK

Correspondence to: R Hovorka, Institute of Metabolic Science,

University of Cambridge, Box 289

Addenbrooke's Hospital,

Cambridge CB2 000, UK

rh347@cam.ac.uk

Cite this as: BMJ 2011;342:d1855 doi:10.1136/bmj.d1855

\section{ABSTRACT}

Objective To compare the safety and efficacy of overnight closed loop delivery of insulin (artificial pancreas) with conventional insulin pump therapy in adults with type 1 diabetes.

Design Two sequential, open label, randomised controlled crossover, single centre studies.

Setting Clinical research facility.

Participants 24 adults (10 men, 14 women) with type 1 diabetes, aged 18-65, who had used insulin pump therapy for at least three months: 12 were tested after consuming a medium sized meal and the other 12 after consuming a larger meal accompanied by alcohol. Intervention During overnight closed loop delivery, sensor measurements of glucose were fed into a computer algorithm, which advised on insulin pump infusion rates at 15 minute intervals. During control nights, conventional insulin pump settings were applied. One study compared closed loop delivery of insulin with conventional pump therapy after a medium sized evening meal ( $60 \mathrm{~g}$ of carbohydrates) at 1900 , depicting the scenario of "eating in." The other study was carried out after a later large evening meal (100 $\mathrm{g}$ of carbohydrates) at 2030, accompanied by white wine $(0.75 \mathrm{~g} / \mathrm{kg}$ ethanol) and depicted the scenario of "eating out."

Main outcome measures The primary outcome was the time plasma glucose levels were in target

(3.91-8.0 $\mathrm{mmol} / \mathrm{L}$ ) during closed loop delivery and a comparable control period. Secondary outcomes included pooled data analysis and time plasma glucose levels were below target ( $\leq 3.9 \mathrm{mmol} / \mathrm{L})$.

Results For the eating in scenario, overnight closed loop delivery of insulin increased the time plasma glucose levels were in target by a median $15 \%$ (interquartile range $3-35 \%), P=0.002$. For the eating out scenario, closed loop delivery increased the time plasma glucose levels were in target by a median $28 \%$ (2-39\%), $P=0.01$. Analysis of pooled data showed that the overall time plasma glucose was in target increased by a median $22 \%$ (3-37\%) with closed loop delivery ( $\mathrm{P}$ <0.001). Closed loop delivery reduced overnight time spent hypoglycaemic (plasma glucose $\leq 3.9 \mathrm{mmol} / \mathrm{L})$ by a median $3 \%(0-20 \%), P=0.04$, and eliminated plasma glucose concentrations below $3.0 \mathrm{mmol} / \mathrm{L}$ after midnight.

Conclusion These two small crossover trials suggest that closed loop delivery of insulin may improve overnight control of glucose levels and reduce the risk of nocturnal hypoglycaemia in adults with type 1 diabetes.

Trial registration ClinicalTrials.gov NCT00910767 and NCT00944619.

\section{INTRODUCTION}

Worldwide, type 1 diabetes accounts for $5-15 \%{ }^{1}$ of 285 million adults with diabetes. ${ }^{2}$ The incidence of type 1 diabetes is increasing at a rate of $3 \%$ per year, with the highest incidence in white European populations, particularly those in northern Europe. ${ }^{3}$ Lifelong insulin replacement is required, but conventional regimens for delivering insulin fail to achieve physiological glucose levels resulting in an increased risk of long term vascular complications. ${ }^{4}$ Although educational interventions have a modest effect on outcomes these are difficult to sustain and cannot alone facilitate optimal glucose control. ${ }^{5}$ A major challenge of intensive insulin therapy is the risk of hypoglycaemia, ${ }^{6}$ with low blood glucose levels typically lasting more than two hours a day, ${ }^{7}$ impeding efforts to optimise glucose control and reducing quality of life. ${ }^{6}$

Since early 2000, improved tools for managing type 1 diabetes have emerged. These include continuous glucose monitors and increasingly sophisticated insulin pumps. Continuous glucose monitors measure interstitial glucose levels and, although less accurate than conventional monitoring by finger stick testing, they offer unprecedented insights into daily glucose excursions $^{8}$ and their regular use improves glucose control. ${ }^{9}$ Insulin pumps are designed to mimic physiological delivery of insulin, with pre-meal doses 
determined according to the carbohydrate content of a planned meal, glucose levels from finger stick testing, and insulin sensitivity factors. ${ }^{10}$ Basal doses are delivered at pre-programmed rates over a 24 hour period and are intermittently adjusted according to finger stick glucose levels. Combining continuous glucose monitoring with pump therapy can improve the control of glucose, ${ }^{11}$ but responding to overnight real time data detected by sensor is impractical. More than half of hypoglycaemic events occur overnight ${ }^{12}$ and the risk of hypoglycaemia increases with alcohol ingestion. ${ }^{13}$ Thus developing measures to prevent nocturnal hypoglycaemia is a priority.

Recent technological advances provide an opportunity to combine three technologies - continuous glucose monitors, insulin pumps, and a computerised control algorithm. This forms the basis of a closed loop system, sometimes termed an artificial pancreas, and characterised by algorithm driven insulin delivery according to glucose levels detected by a sensor. ${ }^{14-16}$ Research is under way to develop closed loop systems of increasing complexity. ${ }^{17}$ We have already shown that overnight closed loop delivery of insulin can improve glucose control and reduce the risk of nocturnal hypoglycaemia in children and adolescents. ${ }^{18}$ Here, we hypothesise that these findings can be extended to adults.

\section{METHODS}

We carried out two sequential, open label, randomised controlled crossover studies comparing the overnight closed loop delivery of insulin with conventional insulin pump (continuous subcutaneous insulin infusion) therapy (fig 1). The studies mimicked the two common scenarios of "eating in" and "eating out" in preparation for testing as an outpatient. In an initial study we evaluated closed loop delivery after a medium sized evening meal, mimicking an evening at home when closed loop delivery could be conveniently started with the meal. In a second, more challenging, study mimicking an evening out, the meal was larger, was consumed later, and was accompanied by wine. Closed loop

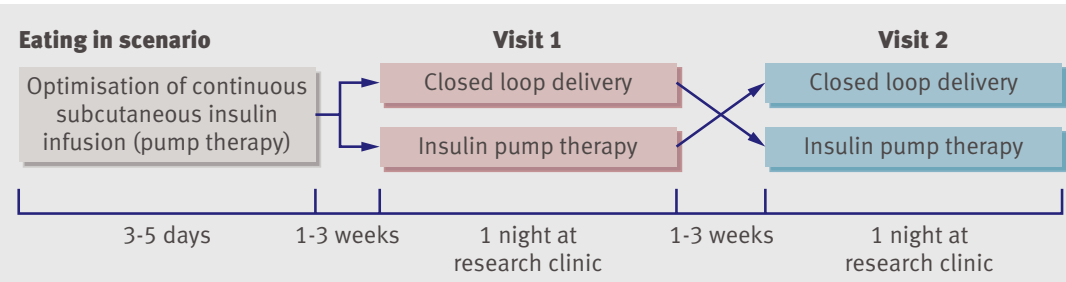

Eating out scenario

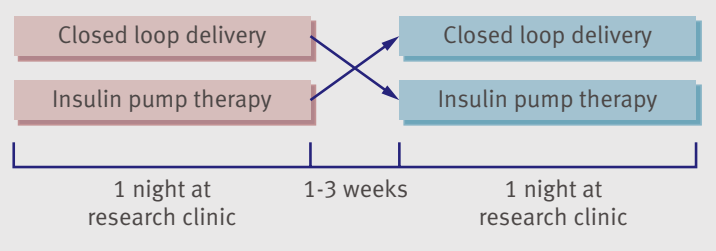

Fig 1| Design of two studies comparing closed loop delivery of insulin with conventional insulin pump therapy after two meal scenarios: eating in and eating out delivery was started later and continued until noon the next day.

\section{Setting and participants}

The studies were carried out at the Wellcome Trust clinical research facility at Addenbrooke's Hospital, Cambridge, between February and December 2009. Inclusion criteria were adults with type 1 diabetes (World Health Organization criteria or confirmed negative for $\mathrm{C}$ peptide), aged 18-65, and using insulin pump therapy for at least three months. Exclusion criteria were awareness of reduced hypoglycaemia and clinically significant nephropathy, neuropathy, or retinopathy. For the eating out scenario, we recruited participants who could tolerate the amount of alcohol used and excluded participants with insulin resistance (total daily insulin dose $\geq 1.4 \mathrm{U} / \mathrm{kg}$ ), with poor glycaemic control $\left(\mathrm{HbA}_{1 \mathrm{c}} \geq 10 \%\right)$, and who were pregnant or breast feeding. Participants signed informed consent. Figure 2 shows the flow of participants through the study.

\section{Eating in scenario}

Of 32 adults invited to take part in the study, 13 agreed and were randomly assigned to be treated overnight with either closed loop delivery of insulin or conventional insulin pump therapy during two study nights, separated by an interval of one to three weeks. Before the first study visit we analysed data from continuous glucose monitoring for up to 120 hours to optimise the delivery of insulin by conventional pump therapy. On both visits participants ate an identical evening meal, comprising $60 \mathrm{~g}$ of carbohydrate, at 1900, accompanied by prandial insulin. We calculated the prandial boluses according to the participants' own insulin to carbohydrate ratio and glucose values from finger stick testing. During the intervention visit, closed loop insulin delivery was applied from 1900 until 0800 the next day. During the control visit, participants applied their usual insulin pump settings over the same timeframe.

\section{Eating out scenario}

We approached a further 41 adults with type 1 diabetes and recruited 12 to a second randomised crossover study of closed loop delivery or conventional insulin pump therapy after a large evening meal accompanied by alcohol, depicting the scenario of "eating out." On both visits, one to three weeks apart, participants ate an identical evening meal, comprising $100 \mathrm{~g}$ of carbohydrate, at 2030, accompanied by prandial insulin and dry white wine (Chenin Blanc, 13\% vol, Ken Forrester Wines, South Africa). Participants drank the wine (7.2 $\mathrm{mL} / \mathrm{kg}$ or 6.6 units per $70 \mathrm{~kg}$ participant) with or after their meal, completing the meal by 2200 . During the intervention visit, insulin was delivered by closed loop from 2200 until 1200 the next day. During the control visit, participants applied their usual insulin pump settings over the same timeframe. 
Table 1|Baseline characteristics of participants completing two meal scenarios to compare closed loop delivery of insulin with conventional insulin pump therapy. Values are means (standard deviations) unless stated otherwise

\begin{tabular}{|c|c|c|c|c|c|c|c|c|}
\hline Meal scenarios & $\begin{array}{l}\text { No of } \\
\text { participants }\end{array}$ & $\begin{array}{l}\text { No of men/No } \\
\text { of women }\end{array}$ & $\begin{array}{c}\text { Age } \\
\text { (years) }\end{array}$ & $\begin{array}{l}\text { Body mass } \\
\text { index }\end{array}$ & $\begin{array}{l}\mathrm{HbA} \\
(\%)^{1 \mathrm{c}}\end{array}$ & $\begin{array}{l}\text { Duration of diabetes } \\
\text { (years) }\end{array}$ & $\begin{array}{l}\text { Duration of pump use } \\
\text { (years) }\end{array}$ & $\begin{array}{l}\text { Total daily insulin dose } \\
\text { (U/kg/day) }\end{array}$ \\
\hline Eating in* & 12 & $5 / 7$ & $37.7(8.5)$ & $24.6(2.6)$ & $7.8(0.5)$ & $21.5(10.0)$ & $2.9(3.5)$ & $0.80(0.20)$ \\
\hline Eating out† & 12 & $5 / 7$ & $37.3(9.9)$ & $26.8(4.2)$ & $7.8(0.7)$ & $19.7(9.7)$ & $1.9(2.6)$ & $0.66(0.13)$ \\
\hline Both scenarios & 24 & $10 / 14$ & $37.5(9.1)$ & $25.7(4.2)$ & $7.8(0.6)$ & $20.6(9.7)$ & $2.4(3.0)$ & $0.73(0.17)$ \\
\hline
\end{tabular}

*Medium sized evening meal (60 g carbohydrate).

tLarge evening meal (100 g carbohydrate) accompanied by alcohol.

\section{Continuous glucose monitoring and insulin delivery}

To measure subcutaneous glucose in the eating in scenario we used the continuous glucose monitoring system FreeStyle Navigator (Abbott Diabetes Care, Alameda, CA) with a 10 hour run-in calibration period. In the eating out scenario we used FreeStyle Navigator with a one hour run-in calibration period. The systems were calibrated using capillary finger stick measurements as per manufacturer's instructions. The accuracy of the sensor, evaluated as the median relative absolute difference between sensor glucose levels and paired plasma glucose levels divided by plasma glucose levels, was 8.0\% (4.5-19.3\%) in the eating in scenario and $12.0 \%(6.8-17.2 \%)$ in the eating out scenario.

When participants arrived at the research clinic, we replaced their insulin pump with a study pump (Deltec Cozmo; Smiths Medical, St Paul, MN). This pump was connected to the established infusion site, delivering rapid acting insulin analogue Aspart (Novo Nordisk, Bagsvaerd, Denmark).

\section{Closed loop algorithm}

We used an algorithm based on the model predictive control approach. ${ }^{18} 19$ Every 15 minutes a research nurse initiated a control cycle; the nurse inputted the sensor glucose value into the computer based

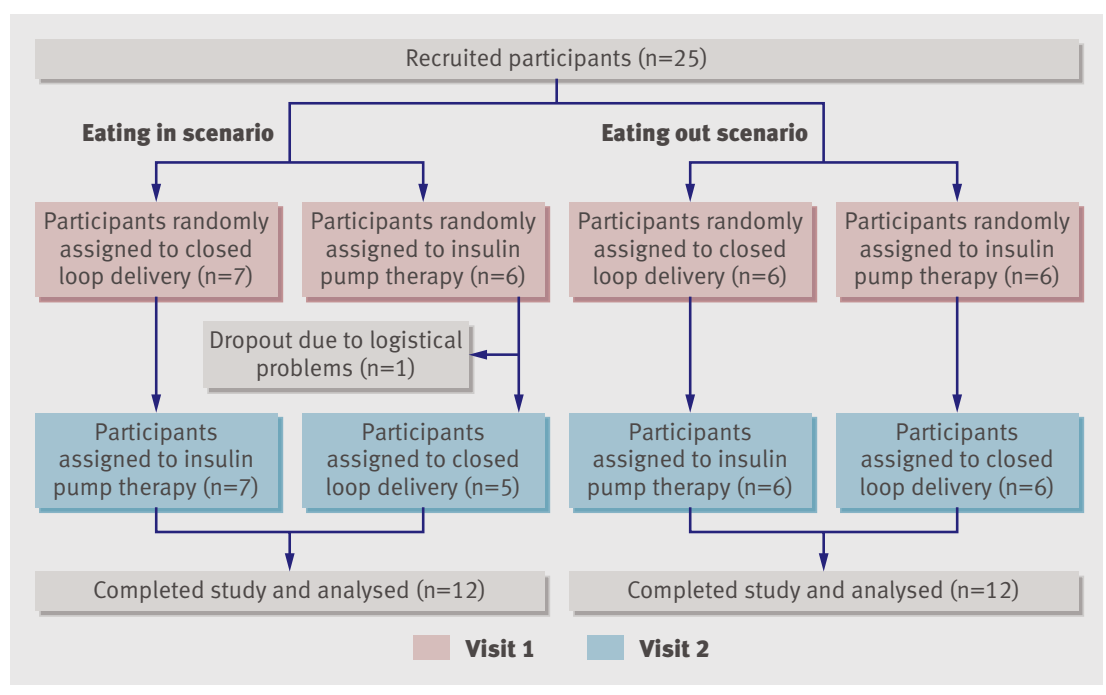

Fig 2 Flow of participants through study comparing closed loop delivery of insulin with conventional insulin pump therapy after a medium sized evening meal (eating in scenario), and study comparing closed loop delivery with insulin pump therapy after a large evening meal accompanied by alcohol (eating out scenario) algorithm and adjusted the insulin pump according to the basal infusion rate calculated by the algorithm. The calculations utilised a compartment model of glucose kinetics, ${ }^{20}$ describing the effect of rapid acting insulin and the carbohydrate content of meals on glucose excursions detected by the sensor. The algorithm was initialised using participant's weight, total daily insulin dose, and basal insulin requirements. Additionally, the algorithm was provided with glucose levels measured by the sensor during a 30 minute period preceding the start of closed loop delivery, the carbohydrate content of the evening meal, and the prandial insulin bolus. The algorithm adapted itself to participants by updating two model variables: an endogenous glucose flux correcting for errors in model based predictions, and carbohydrate bioavailability. Several competing models differing in the absorption of subcutaneous insulin and oral carbohydrates ran in parallel..$^{21} \mathrm{~A}$ combined model forecasted plasma glucose excursions over a 2.5 hour prediction horizon. The algorithm aimed to achieve glucose levels between 5.8 and $7.3 \mathrm{mmol} / \mathrm{L}$ and adjusted the actual level depending on fasting versus postprandial status, preceding glucose levels, and the accuracy of predictions made by the compartment model. Safety rules limited maximum insulin infusion and suspended insulin delivery when the sensor measured glucose at or below $4.3 \mathrm{mmol} / \mathrm{L}$ or when the sensor detected that glucose was decreasing rapidly. We used algorithm version 0.02 .04 to 0.02 .18 .

\section{Plasma glucose and plasma insulin sampling}

We collected venous samples for glucose determination every 15 minutes and for insulin assay every 30 minutes. In the eating in scenario we collected samples between 1830 and 0800 and in the eating out scenario between 1930 and 1200. These data were not used to alter insulin infusion rates during the visits for closed loop delivery or control. In the eating out scenario we collected additional samples for determination of ethanol at 2030, 2200, and midnight and then three hourly until 1200 the next day.

\section{Assays}

We used YSI2300 STAT Plus Analyser (YSI, Lynchford House, Farnborough, UK) to determine plasma glucose levels, and an immunochemiluminometric assay (Invitron; Monmouth, UK) with an intra-assay coefficient of variation of $4.7 \%$ and an interassay coefficient of variation of $7.2 \%$ to $8.1 \%$ for plasma insulin assay. We determined plasma ethanol levels using the 
Table 2| Time plasma glucose level in target during closed loop delivery of insulin and conventional insulin pump therapy in two meal scenarios. Values are medians (interquartile ranges) unless stated otherwise

\begin{tabular}{|c|c|c|c|c|}
\hline \multirow[b]{2}{*}{ Meal scenarios } & \multicolumn{2}{|c|}{ Time (\%) when plasma glucose in target range* } & \multirow{2}{*}{$\begin{array}{l}\text { Paired difference } \dagger \\
(\%)(n=12)\end{array}$} & \multirow[b]{2}{*}{ P value } \\
\hline & Closed loop $(n=12)$ & Insulin pump $(n=12)$ & & \\
\hline Eating in $\ddagger$ & 80 (60 to 94$)$ & $51(39$ to 75$)$ & 15 (3 to 35$)$ & 0.002 \\
\hline Eating out§ & $70(60$ to 86$)$ & $47(28$ to 66$)$ & 28 (2 to 39$)$ & 0.01 \\
\hline
\end{tabular}

*Target range 3.91-8.0 mmol/L.

†Closed loop minus insulin pump. Positive value indicates measurement was higher on night of closed loop delivery compared with night of pump therapy.

$\ddagger$ Closed loop delivery from 1900 to 0800 .

$\S$ Closed loop delivery from 2200 to 1200 .

ethyl alcohol method (Dade Behring, Atterbury, UK), with an intra-assay coefficient of variation of $2.4 \%$ and an interassay coefficient of variation of $5.71 \%$.

\section{Sample size}

Based on previous studies ${ }^{18}$ we anticipated that overnight closed loop delivery would increase the time that plasma glucose concentrations were between 3.91 and $8.00 \mathrm{mmol} / \mathrm{L}$ by a mean $37 \%$ (SD $40 \%)$. We calculated that 12 participants would provide $80 \%$ power at the
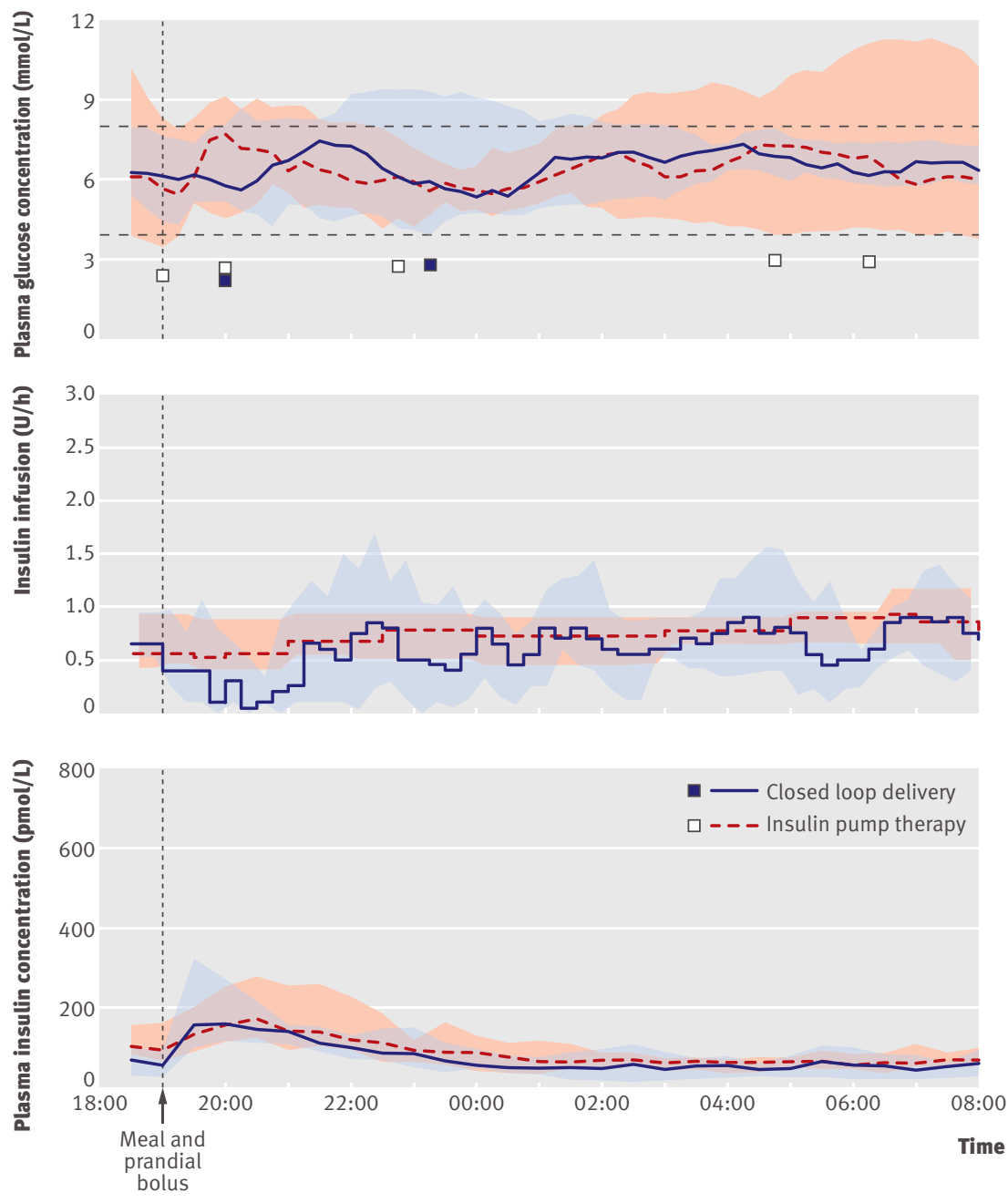

Fig 3 | Profiles (medians and interquartile ranges) of plasma glucose and insulin concentrations and insulin infusion in eating in scenario (12 participants). Outlying squares represent hypoglycaemic events (glucose level $\ll 3.0 \mathrm{mmol} / \mathrm{L}$ )
$5 \%$ level of significance to detect this difference between conventional and closed loop insulin delivery systems.

\section{Randomisation and masking}

For each study we placed a computer generated allocation sequence with permuted block four randomisation in sealed envelopes. Participants were randomised on recruitment. During the eating in scenario, investigators were blinded to the plasma glucose data. For safety reasons, during the eating out scenario investigators had access to plasma glucose levels. During both studies, participants did not have access to data on plasma or sensor glucose levels.

\section{Statistical analysis}

Senior investigators and study statisticians agreed on the analysis plan in advance. The primary outcome was the percentage time plasma glucose concentrations were in the target range $(3.91-8.00 \mathrm{mmol} / \mathrm{L}$ ) between 1900 and 0800 in the eating in scenario and between 2200 and 1200 in the eating out scenario. Secondary outcomes were the mean glucose concentration, time when glucose concentration was $3.9 \mathrm{mmol} / \mathrm{L}$ or less (hypoglycaemia), time when glucose concentration was greater than $8.0 \mathrm{mmol} / \mathrm{L}$ (hyperglycaemia), mean rate of insulin infusion, and mean plasma insulin concentration for both separate and pooled study data. We estimated glycaemic variability by mean amplitude of glycaemic excursions ${ }^{22}$ and standard deviation of glucose concentration. Secondary outcomes were calculated for both plasma and sensor glucose levels as well as for the period from midnight to end of closed loop control.

We used the low blood glucose index to assess the duration and extent of hypoglycaemia, calculated as an average of transformed glucose measurements progressively increasing at low glucose levels. ${ }^{23}$ Safety assessments examined plasma glucose levels below $3 \mathrm{mmol} / \mathrm{L}$ and above $16.7 \mathrm{mmol} / \mathrm{L}$.

For each outcome we fit a repeated measures regression model based on the ranked normal transformation (except for the mean glucose concentration which was not transformed because it already had an approximate normal distribution) to compare the two treatments adjusting for plasma glucose level at the start of closed loop delivery. We carried out analyses using SAS software, version 9.1 and SPSS, version 15 Kernel density of plasma glucose was estimated using the package "np" (non-parametric kernel smoothing methods for mixed data types), version 0.40 -1, adopting a bandwidth of $0.25 \mathrm{mmol} / \mathrm{L}$ and implemented in the R, version 2.11.1 (R Foundation for Statistical Computing).

\section{RESULTS}

Eating in scenario

One participant who was unable to attend the second visit for logistical reasons withdrew and was excluded from the analysis. Table 1 shows the baseline characteristics of the remaining participants. Figure 3 shows 
Table 3 Secondary comparisons in eating in scenario based on plasma glucose concentrations. Values are medians (interquartile ranges) unless stated otherwise

\begin{tabular}{|c|c|c|c|c|}
\hline \multirow[b]{2}{*}{ Period and outcome } & \multicolumn{2}{|c|}{ Insulin delivery system } & \multirow[b]{2}{*}{$\begin{array}{l}\text { Paired difference* } \\
\qquad(n=12)\end{array}$} & \multirow[b]{2}{*}{$P$ value } \\
\hline & $\begin{array}{l}\text { Closed loop } \\
\qquad(n=12)\end{array}$ & $\begin{array}{l}\text { Insulin pump } \\
\qquad(\mathrm{n}=12)\end{array}$ & & \\
\hline \multicolumn{5}{|l|}{ From start of closed loop delivery† } \\
\hline $\begin{array}{l}\text { Mean (SD) plasma glucose level at start of closed loop delivery } \\
(\mathrm{mmol} / \mathrm{L})\end{array}$ & $6.1(1.5)$ & $5.9(2.7)$ & $0.2(3.8)$ & - \\
\hline Mean (SD) overnight plasma glucose level (mmol/L) & $6.7(1.4)$ & $6.7(1.5)$ & $0.0(1.0)$ & 0.98 \\
\hline SD of overnight plasma glucose level (mmol/L) & $1.2(0.9$ to 1.4$)$ & 1.8 (1.3 to 2.3$)$ & $-0.5(-1.0$ to -0.1$)$ & 0.02 \\
\hline Mean amplitude of glucose excursions (mmol/L) & $2.6(2.0$ to 3.7$)$ & $4.6(3.4$ to 5.4$)$ & $-1.7(-3.7$ to -0.4$)$ & 0.03 \\
\hline \multicolumn{5}{|l|}{ Time spent at plasma glucose level (\%): } \\
\hline$\leq 3.5 \mathrm{mmol} / \mathrm{L}$ & 0 (0 to 3$)$ & $1(0$ to 14$)$ & $-1(-11$ to 0$)$ & 0.09 \\
\hline$\leq 3.90 \mathrm{mmol} / \mathrm{L}$ & $1(0$ to 9$)$ & $3(0$ to 25$)$ & $-3(-18$ to 0$)$ & 0.19 \\
\hline$>8.0 \mathrm{mmol} / \mathrm{L}$ & 11 (0 to 38$)$ & 27 (11 to 50$)$ & $-8(-15$ to 1$)$ & 0.01 \\
\hline Low blood glucose index & $0.8(0.0$ to 2.2$)$ & $1.5(0.5$ to 4.4$)$ & $-0.8(-2.8$ to -0.2$)$ & 0.03 \\
\hline Insulin infusion (U/h) & 0.7 (0.5 to 0.8$)$ & $0.8(0.6$ to 0.9$)$ & $0.0(-0.2$ to 0.1$)$ & 0.41 \\
\hline Insulin concentration (pmol/L) & $76(52$ to 104$)$ & $96(65$ to 124$)$ & $-4(-15$ to 1$)$ & 0.22 \\
\hline \multicolumn{5}{|l|}{ After midnight $\ddagger$} \\
\hline Mean (SD) overnight plasma glucose level (mmol/L) & $6.7(1.3)$ & $6.8(2.3)$ & $-0.1(1.6)$ & 0.91 \\
\hline SD overnight plasma glucose level (mmol/L) & $0.8(0.6$ to 1.1$)$ & 0.9 (0.6 to 1.9$)$ & $0.0(-1.0$ to 0.3$)$ & 0.55 \\
\hline Mean amplitude of glucose excursions (mmol/L) & $2.6(1.7$ to 3.0$)$ & 2.7 (1.4 to 4.2$)$ & $0.2(-2.2$ to 0.6$)$ & 0.59 \\
\hline Time plasma glucose level spent in target (\%)§ & $92(70$ to 100$)$ & $45(27$ to 80$)$ & 29 (6 to 46$)$ & 0.003 \\
\hline \multicolumn{5}{|l|}{ Time spent at plasma glucose level (\%): } \\
\hline$\leq 3.5 \mathrm{mmol} / \mathrm{L}$ & $0(0$ to 0$)$ & $0(0$ to 11$)$ & $0(-11$ to 0$)$ & 0.03 \\
\hline$\leq 3.90 \mathrm{mmol} / \mathrm{L}$ & $0(0$ to 0$)$ & $0(0$ to 23$)$ & $0(-23$ to 0$)$ & 0.15 \\
\hline$>8.0 \mathrm{mmol} / \mathrm{L}$ & 1.6 (0 to 29$)$ & 24 (0 to 70$)$ & $-8(-29$ to 0$)$ & 0.01 \\
\hline Low blood glucose index & 0.1 (0.0 to 0.8$)$ & 0.7 (0.1 to 4.9$)$ & $-0.4(-4.3$ to -0.0$)$ & 0.02 \\
\hline Insulin infusion (U/h) & $0.8(0.6$ to 0.9$)$ & 0.8 (0.6 to 0.9$)$ & $0.1(-0.2$ to 0.2$)$ & 0.89 \\
\hline Insulin concentration (pmol/L) & 51 (31 to 81) & 70 (50 to 82$)$ & $-7(-20$ to 10$)$ & 0.23 \\
\hline \multicolumn{5}{|c|}{$\begin{array}{l}{ }^{\star} \text { Closed loop minus insulin pump. Positive value indicates measurement was higher on night of closed loop delivery compared with night of insulin } \\
\text { pump therapy. } \\
\text { †From start of closed loop control at } 1900 \text { to } 0800 \text { in eating in scenario. } \\
\ddagger \text { From midnight to } 0800 \text { in eating in scenario. } \\
\text { §Target range } 3.91-8.0 \mathrm{mmol} / \mathrm{L} \text {. }\end{array}$} \\
\hline
\end{tabular}

the profiles of plasma glucose and plasma insulin concentrations and insulin infusion. The time spent with plasma glucose levels in target range increased by $15 \%$ (3-35\%) during closed loop delivery $(\mathrm{P}=0.002$; table 2$)$. Closed loop delivery decreased glucose variability overnight (reduced standard deviation of plasma glucose $1.2 v 1.8 \mathrm{mmol} / \mathrm{L}, \mathrm{P}=0.02$; table 3). It also decreased the time spent hyperglycaemic $(11 \%$ v $27 \%, \mathrm{P}=0.01)$ and the low blood glucose index (0.8 v $1.5, \mathrm{P}=0.03)$. Insulin infusion was more variable during closed loop delivery, but the average insulin infusion rate and plasma insulin concentrations were similar during closed loop delivery and control visits (fig 3).

From midnight, when participants were sleeping, closed loop delivery achieved near normal glycaemia, with plasma glucose levels in target range for $92 \%$ of the time (interquartile range 70-100\%) compared with $45 \%(27-80 \%)$ on control nights, with a difference of $29 \%(6-46 \%)$ favouring closed loop delivery $(\mathrm{P}=0.003)$.

\section{The eating out scenario}

Table 1 shows the characteristics of the participants. Use of alcohol during closed loop delivery and control visits was comparable (peak ethanol concentration
15.0 (13.7-18.0) mmol/L v $16.5(14.2-20.8) \mathrm{mmol} / \mathrm{L})$ as was time to peak ethanol concentration (150 (90210) minutes $v 90$ (90-90) minutes) and area under the concentration curve per 15.5 hours (4151 (3375-4779) $\mathrm{mmol} / \mathrm{L} v 4766$ (3020-5374) mmol/L). Alcohol ingestion did not affect the performance of closed loop delivery, which increased the time plasma glucose was in target range by $22 \%(3-37 \%), \mathrm{P}=0.01$.

Table 4 shows secondary outcomes, all favouring closed loop delivery of insulin. As for the eating in scenario, the average overnight infusion of insulin and plasma insulin concentration during closed loop delivery and pump therapy were comparable. The profiles for glucose and insulin levels showed lower variability of plasma glucose during closed loop delivery from 0200 onwards (fig 4).

\section{Hypoglycaemic and hyperglycaemic events}

During closed loop delivery, four hypoglycaemic events (glucose level $<3.0 \mathrm{mmol} / \mathrm{L}$ ) were observed, two in the eating in scenario and two in the eating out scenario. All occurred before midnight and all were associated with symptoms. Three were attributable to the preceding prandial insulin dose and could not be 
Table 4 | Secondary comparisons in eating out scenario based on plasma glucose concentrations. Data are medians (interquartile ranges) unless stated otherwise

\begin{tabular}{|c|c|c|c|c|}
\hline \multirow[b]{2}{*}{ Period and outcome } & \multicolumn{2}{|c|}{ Insulin delivery system } & \multirow[b]{2}{*}{$\begin{array}{l}\text { Paired difference* } \\
\qquad(n=12)\end{array}$} & \multirow[b]{2}{*}{$P$ value } \\
\hline & $\begin{array}{l}\text { Closed loop } \\
\quad(n=12)\end{array}$ & $\begin{array}{l}\text { Insulin pump } \\
\qquad(n=12)\end{array}$ & & \\
\hline \multicolumn{5}{|l|}{ From start of closed loop deliveryt } \\
\hline Mean (SD) plasma glucose level at start (mmol/L) & $8.1(3.5)$ & $9.5(3.8)$ & $-1.4(4.5)$ & - \\
\hline Mean (SD) overnight plasma glucose level (mmol/L) & $6.8(0.8)$ & $6.9(1.6)$ & $-0.1(1.3)$ & 0.68 \\
\hline SD of overnight plasma glucose level (mmol/L) & $1.7(1.3$ to 2.0$)$ & $2.2(1.8$ to 2.8$)$ & $-0.5(-0.9$ to 0.1$)$ & 0.06 \\
\hline Mean amplitude of glucose excursions (mmol/L) & $3.8(3.5$ to 5.4$)$ & $6.6(4.3$ to 8.8$)$ & $-1.2(-5.2$ to 0.0$)$ & 0.16 \\
\hline \multicolumn{5}{|l|}{ Time spent at plasma glucose level (\%): } \\
\hline$\leq 3.5 \mathrm{mmol} / \mathrm{L}$ & $1(0$ to 6$)$ & $8(0$ to 18$)$ & $-3(-14$ to 2$)$ & 0.13 \\
\hline$\leq 3.90 \mathrm{mmol} / \mathrm{L}$ & $4(0$ to 10$)$ & $14(0$ to 26$)$ & $-5(-22$ to 4$)$ & 0.21 \\
\hline$>8.0 \mathrm{mmol} / \mathrm{L}$ & 23 (10 to 36$)$ & 31 (12 to 57$)$ & $-21(-31$ to 6$)$ & 0.12 \\
\hline Low blood glucose index & $1.2(0.7$ to 1.8$)$ & $2.8(0.6$ to 4.7$)$ & $-0.9(-3.2$ to 0.5$)$ & 0.37 \\
\hline Insulin infusion (U/h) & $0.8(0.6$ to 1.1$)$ & 0.9 (0.6 to 1.1$)$ & $0.1(-0.1$ to 0.2$)$ & 0.65 \\
\hline Insulin concentration (pmol/L) & 139 (102 to 174$)$ & 129 (105 to 208) & $-8(-17$ to 7$)$ & 0.59 \\
\hline \multicolumn{5}{|l|}{ After midnight $\ddagger$} \\
\hline Mean (SD) overnight plasma glucose level (mmol/L) & $6.7(0.6)$ & $6.8(2.1)$ & $-0.1(1.8)$ & 0.61 \\
\hline SD of overnight plasma glucose level (mmol/L) & $1.5(1.3$ to 1.9$)$ & $1.8(1.0$ to 2.3$)$ & $-0.3(-0.7$ to 0.6$)$ & 0.46 \\
\hline Mean amplitude of glucose excursions (mmol/L) & $3.8(2.9$ to 5.1$)$ & $4.3(3.5$ to 7.2$)$ & $-0.4(-3.5$ to 1.2$)$ & 0.34 \\
\hline Time plasma glucose level spent in target (\%) & $74(63$ to 87$)$ & $53(27$ to 67$)$ & $33(4$ to 41$)$ & 0.005 \\
\hline \multicolumn{5}{|l|}{ Time spent at plasma glucose level (\%): } \\
\hline$\leq 3.5 \mathrm{mmol} / \mathrm{L}$ & $0(0$ to 2$)$ & $5(0$ to 19$)$ & $-1(-19$ to 0$)$ & 0.12 \\
\hline$\leq 3.90 \mathrm{mmol} / \mathrm{L}$ & $0(0$ to 4$)$ & $9(0$ to 27$)$ & $-1(-26$ to 0$)$ & 0.25 \\
\hline $18.0 \mathrm{mmol} / \mathrm{L}$ & 20 (9 to 35$)$ & $31(0$ to 64$)$ & $-16(-41$ to 12$)$ & 0.37 \\
\hline Low blood glucose index & $0.6(0.5$ to 1.3$)$ & $2.0(0.3$ to 4.9$)$ & $-0.7(-4.0$ to 0.1$)$ & 0.55 \\
\hline Insulin infusion $(\mathrm{U} / \mathrm{h})$ & $0.9(0.7$ to 1.1$)$ & $0.9(0.6$ to 1.1$)$ & $0.1(0.0$ to 0.3$)$ & 0.36 \\
\hline Insulin concentration (pmol/L) & $118(77$ to 135$)$ & 100 (75 to 149$)$ & $3(-13$ to 19$)$ & 0.80 \\
\hline \multicolumn{5}{|c|}{$\begin{array}{l}\text { *Closed loop delivery minus pump therapy. Positive value indicates measurement was higher on night of closed loop delivery compared with night } \\
\text { pump therapy. } \\
\text { †From start of closed loop control at } 2200 \text { to } 1200 \text { in eating out scenario. } \\
\text { †From midnight to } 1200 \text { in eating out scenario. } \\
\text { §Target range } 3.91-8.0 \mathrm{mmol} / \mathrm{L} \text {. }\end{array}$} \\
\hline
\end{tabular}

prevented despite suspended insulin delivery immediately after the start of closed loop. Three episodes were treated with 15-36 $\mathrm{g}$ of oral carbohydrates in drink (Lucozade; GlaxoSmithKline, Brentford, UK) and the fourth lasted 30 minutes with spontaneous recovery. When data collected after midnight, while participants slept, were combined (968 readings), no plasma glucose measurement was below $3.0 \mathrm{mmol} / \mathrm{L}, 7(<1 \%)$ were below $3.3 \mathrm{mmol} / \mathrm{L}$, and $8(<1 \%)$ were below $3.5 \mathrm{mmol} / \mathrm{L}$.

During insulin pump therapy, one hypoglycaemic episode with glucose level below $2.0 \mathrm{mmol} / \mathrm{L}$ occurred at 0215 in the eating out scenario. The episode was not associated with symptoms but was treated with $30 \mathrm{~g}$ of oral carbohydrates in drink. That study night was terminated, as per protocol. Another six hypoglycaemic events with glucose levels below $3.0 \mathrm{mmol} / \mathrm{L}$ occurred, five in the eating in scenario and one in the eating out scenario. Two were associated with symptoms and together with another event at $3.0 \mathrm{mmol} / \mathrm{L}$, which also occurred before 0100 , were treated with $15-18 \mathrm{~g}$ oral carbohydrates in drink. The remaining four events were not associated with symptoms; all but one event occurred after 0100 and were not treated. When data collected after midnight were combined (939 readings),
$2(<1 \%)$ plasma glucose values were below $2.5 \mathrm{mmol} / \mathrm{L}$, $10(1 \%)$ were below $3.0 \mathrm{mmol} / \mathrm{L}, 41(4 \%)$ were below $3.3 \mathrm{mmol} / \mathrm{L}$, and $72(8 \%)$ were below $3.5 \mathrm{mmol} / \mathrm{L}$.

No hyperglycaemic events (glucose concentrations above $16.7 \mathrm{mmol} / \mathrm{l}$ ) occurred during either treatment. After midnight, all plasma glucose concentrations during closed loop delivery were below $12 \mathrm{mmol} / \mathrm{L}$ and during pump therapy were below $13.5 \mathrm{mmol} / \mathrm{L}$.

Pooled analysis of studies

When data from both studies were combined, closed loop delivery increased the time when plasma glucose was in target by $22 \%(3-37 \%), \mathrm{P}<0.001$. Closed loop delivery reduced overnight time spent below target by $3 \%(0-20 \%), \mathrm{P}=0.04$. Closed loop delivery significantly reduced the variability in plasma glucose levels and reduced time when the levels were above target (table 5). Closed loop delivery consistently outperformed conventional insulin pump therapy at both high and low glucose values (fig 5).

\section{DISCUSSION}

Overnight closed loop delivery of insulin improved glucose control and reduced exposure to low plasma glucose levels in adults with type 1 diabetes, even after 

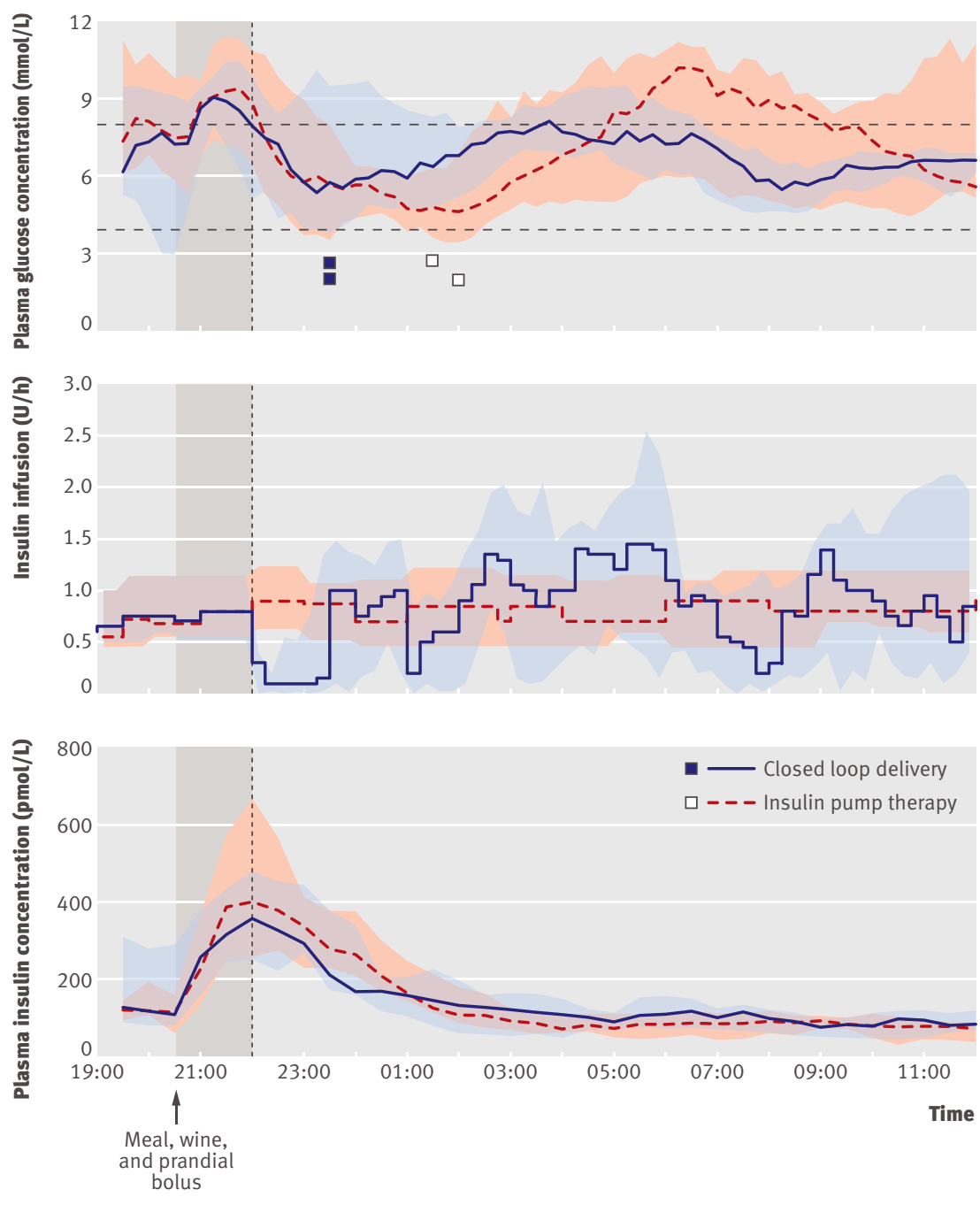

Fig 4 | Profiles (medians and interquartile ranges) of plasma glucose and insulin concentrations and insulin infusion in the eating out scenario (12 participants). Outlying squares represent hypoglycaemic events (glucose level $<3.0 \mathrm{mmol} / \mathrm{L}$ )

a large carbohydrate meal accompanied by alcohol. The time plasma glucose levels were at or below $3.9 \mathrm{mmol} / \mathrm{L}$ was halved, and after midnight we did not observe plasma glucose values below $3.0 \mathrm{mmol} / \mathrm{L}$. The average dose of insulin delivered during closed loop and conventional pump therapy was comparable, illustrating the key role of glucose responsive insulin delivery to achieve target glucose levels. The large evening meal and alcohol intake provided a greater challenge to closed loop delivery than did a medium sized evening meal, reflected by a slightly reduced but still superior performance over insulin pump therapy.

\section{Strengths and limitations of the study}

An important feature of our closed loop algorithm is avoidance of hypoglycaemia, which if replicated in the home setting would revolutionise patient safety. The algorithm suspends insulin delivery when the sensor detects a low or rapid fall in glucose levels and does so without increased risk of hyperglycaemia. ${ }^{24}$ Initiation of the algorithm is straightforward, requiring users to input their weight, total daily insulin dose, and basal infusion rates. The system updates advice on insulin dose using a robust, computationally efficient approach suitable for use with insulin pumps and hand held devices to facilitate practical use. It can discriminate between slowly or rapidly absorbed meals, thus coping with considerable variability in gut absorption. Similarly, variability in insulin absorption is assessed through model based analysis of insulin delivery and the effects on sensor glucose levels. These adaptive capabilities set our algorithm apart from most existing non-adaptive approaches. ${ }^{25-27}$

Additional strengths of our study are that we used the closed loop system in circumstances near to those in real life, without artificially improving performance. Firstly, we used a commercially available continuous glucose monitor calibrated according to manufacturer's instructions. Secondly, only one sensor was inserted and it was not recalibrated in the event of suboptimal accuracy. Thirdly, the advice of the algorithm was always adhered to. Our studies assessed closed loop delivery of insulin in preparation for home testing, when recalibration of a sensor is impractical (particularly overnight), and multiple sensors, although improving accuracy, are inconvenient and likely to affect users' satisfaction.

Limitations are that participants were compliant and predominantly of white ethnicity, hence applicability to less compliant people and those with poor glycaemic control is unknown. Also, we did not adjust for multiple statistical comparisons in secondary outcomes; hence these should be considered hypothesis generating rather than conclusive. Another limitation is that the research nurse manually entered sensor glucose values into the algorithm and manually adjusted the insulin pump. Presumably the lack of automation did not to affect the performance of the closed loop system but will need to be dealt with before proceeding to home testing. The evening meals were standardised for carbohydrate but not for fat or protein content, but given that identical meals were eaten on both study occasions, this should not affect the results.

\section{Comparison with other studies}

Our earlier studies described the benefits of overnight closed loop delivery of insulin in children and adolescents after a large evening meal and moderate exercise. ${ }^{18}$ They documented a $20 \%$ increase in the time that plasma glucose levels were in target and a halving of the time spent hypoglycaemic with the same closed loop algorithm. ${ }^{18}$ The present study provides further evidence that overnight closed loop delivery can operate safely, effectively, and consistently across different age groups, insulin sensitivities, and lifestyle conditions, including large evening meals, evening exercise, and alcohol intake.

After the evening intake of alcohol, we expected late morning hypoglycaemia during conventional insulin pump therapy, as observed in a previous study ${ }^{28}$ at similar ethanol concentrations. This may be attributed to differences in protocol as we opted to omit breakfast 
Table 5 |Comparisons between closed loop delivery of insulin and conventional insulin pump therapy based on plasma glucose concentrations after pooling results for two meal scenarios: eating in and eating out. Data are medians (interquartile ranges) unless stated otherwise

\begin{tabular}{|c|c|c|c|c|}
\hline \multirow[b]{2}{*}{ Period and outcome } & \multicolumn{2}{|c|}{ Insulin delivery system } & \multirow[b]{2}{*}{$\begin{array}{l}\text { Paired difference* } \\
\qquad(n=24)\end{array}$} & \multirow[b]{2}{*}{$P$ value } \\
\hline & $\begin{array}{c}\text { Closed loop } \\
\quad(n=24)\end{array}$ & $\begin{array}{l}\text { Insulin pump } \\
\qquad(n=24)\end{array}$ & & \\
\hline \multicolumn{5}{|l|}{ From start of closed loop delivery† } \\
\hline Mean (SD) plasma glucose level at start (mmol/L) & $7.1(2.8)$ & $7.7(3.7)$ & $-0.6(4.2)$ & - \\
\hline Mean (SD) overnight plasma glucose level (mmol/L) & $6.7(1.1)$ & $6.8(1.5)$ & $-0.1(1.1)$ & 0.84 \\
\hline SD of overnight plasma glucose level (mmol/L) & $1.4(1.1$ to 1.8$)$ & $2.0(1.6$ to 2.7$)$ & $-0.5(-1.0$ to -0.1$)$ & 0.001 \\
\hline Mean amplitude of glucose excursions (mmol/l) & $3.6(2.4$ to 4.0$)$ & $5.0(3.6$ to 8.4$)$ & $-1.5(-4.0$ to 0.0$)$ & 0.003 \\
\hline Time plasma glucose level spent in target (\%) & $76(60$ to 88$)$ & $50(32$ to 70$)$ & 22 (3 to 37$)$ & $<0.001$ \\
\hline \multicolumn{5}{|l|}{ Time spent at plasma glucose level (\%): } \\
\hline$\leq 3.5 \mathrm{mmol} / \mathrm{L}$ & $0(0$ to 4$)$ & $4(0$ to 17$)$ & $-1(-12$ to 0$)$ & 0.02 \\
\hline$\leq 3.90 \mathrm{mmol} / \mathrm{L}$ & $3(0$ to 9$)$ & $7(0$ to 25$)$ & $-3(-20$ to 0$)$ & 0.04 \\
\hline$>8.0 \mathrm{mmol} / \mathrm{L}$ & 18 (2 to 36$)$ & $30(12$ to 54$)$ & $-11(-30$ to 1$)$ & 0.006 \\
\hline Low blood glucose index & $1.0(0.5$ to 2.0$)$ & $1.9(0.5$ to 4.5$)$ & $-0.9(-3.0$ to 0.1$)$ & 0.01 \\
\hline Insulin infusion (U/h) & $0.8(0.6$ to 1.0$)$ & $0.8(0.6$ to 1.0$)$ & $0.0(-0.1$ to 0.2$)$ & 0.83 \\
\hline Insulin concentration (pmol/L) & 104 (68 to 148$)$ & 109 (91 to 159$)$ & $-7(-16$ to 2$)$ & 0.14 \\
\hline \multicolumn{5}{|l|}{ After midnight $\ddagger$} \\
\hline Overnight plasma glucose level (mmol/L) & $6.7(1.0)$ & $6.8(2.2)$ & $-0.1(1.7)$ & 0.66 \\
\hline SD of overnight plasma glucose level (mmol/L) & $1.2(0.8$ to 1.5$)$ & $1.5(0.7$ to 2.0$)$ & $-0.2(-0.8$ to 0.4$)$ & 0.28 \\
\hline Mean amplitude of glucose excursions (mmol/L) & $2.9(2.3$ to 4.1$)$ & $3.9(1.8$ to 5.6$)$ & $-0.1(-2.5$ to 0.9$)$ & 0.27 \\
\hline Time plasma glucose spent in target (\%)§ & 81 (63 to 99$)$ & $51(27$ to 67$)$ & $32(6$ to 43$)$ & $<0.001$ \\
\hline \multicolumn{5}{|l|}{ Time spent at plasma glucose level (\%): } \\
\hline$\leq 3.5 \mathrm{mmol} / \mathrm{L}$ & 0 (0 to 0$)$ & 0 (0 to 17$)$ & $0(-17$ to 0$)$ & 0.007 \\
\hline$\leq 3.90 \mathrm{mmol} / \mathrm{L}$ & $0(0$ to 3$)$ & 0 (0 to 27$)$ & $0(-26$ to 0$)$ & 0.04 \\
\hline$>8.0 \mathrm{mmol} / \mathrm{L}$ & $13(0$ to 34$)$ & $31(0$ to 67$)$ & $-8(-37$ to 1$)$ & 0.09 \\
\hline Low blood glucose index & $0.5(0.1$ to 1.1$)$ & $1.2(0.2$ to 4.9$)$ & $-0.6(-4.0$ to -0.0$)$ & 0.02 \\
\hline Insulin infusion $(\mathrm{U} / \mathrm{h})$ & $0.9(0.6$ to 1.0$)$ & $0.9(0.6$ to 1.0$)$ & $0.1(-0.1$ to 0.2$)$ & 0.46 \\
\hline Insulin concentration (pmol/L) & 81 (48 to 127$)$ & 78 (69 to 124$)$ & $1(-16$ to 13$)$ & 0.20 \\
\hline
\end{tabular}

and its meal related bolus to mimic sleeping until lunchtime (not uncommon in young adults). Another difference was that in our study alcohol was consumed within two hours of the evening meal compared with three hours later in the other study. Nevertheless, our data confirm that alcohol ingestion is unlikely to interfere with closed loop delivery of insulin.

Recently, several studies of overnight and day and night closed loop delivery have been reported. ${ }^{25-2729}$ None had a randomised study design and most evaluated algorithm performance rather than its clinical application. Further studies are required to quantify the barriers and benefits of novel approaches, including fully automated insulin delivery, use of glucagon, ${ }^{2729}$ and intraperitoneal insulin delivery. ${ }^{30}$ Testing in the home setting and over several nights is now needed to determine the effectiveness on longer term glycaemic control.

\section{Conclusions and policy implications}

Introduction of closed loop systems for the delivery of insulin into clinical practice and clinical decision

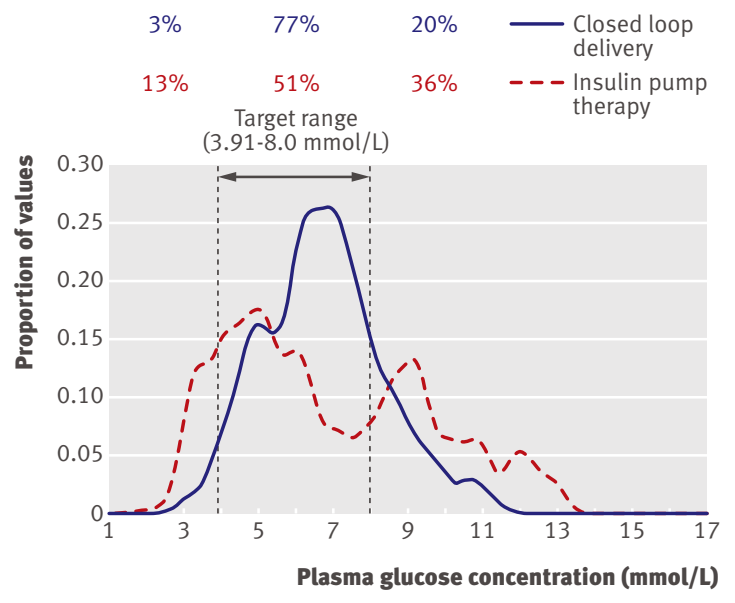

Fig 5 | Distribution of plasma glucose values during closed loop insulin delivery and conventional insulin pump therapy (continuous subcutaneous insulin infusion) combining data collected from midnight until end of the eating in scenario and the eating out scenario. Percentages represent total time plasma glucose level was below, at, and above target from midnight until end of closed loop delivery 


\section{WHAT IS ALREADY KNOWN ON THIS TOPIC}

Combined continuous glucose monitoring and insulin pump therapy improves glucose control in adults with type 1 diabetes, but requires ongoing patient education and motivation

Closed loop systems combine three technologies, linking real time insulin delivery with continuous glucose monitoring via a control algorithm, to replace or assist clinical decision making

Overnight closed loop insulin delivery reduces glucose excursions in children and adolescents after large meals and exercise, but efficacy in adults is unknown

\section{WHAT THIS STUDY ADDS}

In these two small crossover trials overnight closed loop delivery of insulin (artificial pancreas) in adults with type 1 diabetes improved glucose control and reduced exposure to low plasma glucose levels, with no overnight values below $3.0 \mathrm{mmol} / \mathrm{L}$

Overnight closed loop delivery can operate safely, effectively, and consistently across different age groups, insulin sensitivities, and lifestyle conditions, including large evening meals and alcohol intake
Competing interests: All authors have completed the Unified Competing Interest form at www.icmje.org/coi_disclosure.pdf (available on request from the corresponding author) and declare: in the previous 3 years $\mathrm{RH}$ has received speaker honorariums from Minimed Medtronic, Lifescan, and Novo Nordisk, served on advisory panel for Animas and Minimed Medtronic, received licence fees from BBraun and Beckton Dickinson, and served as a consultant to Beckton Dickinson, BBraun, and Profil; CK has served as a consultant to Medtronic International Trading Sàrl and Diabetes Technology Management; SAA has served on advisory boards for Medtronic and Johnson and Johnson and has received speaker honorariums for Medtronic, Animas, and Roche; SRH has received speaker honorariums from NovoNordisk, Eli Lilly, Sanofi-Aventis, and Lifescan and served on advisory panels for NovoNordisk and Eli Lily; MLE has received speaker honorariums from Eli Lilly and served on advisory panels for Medtronic, Sanofi-Aventis, and Cellnovo; HRM has received speaker honorariums from Minimed Medtronic: MEW has received license fees from Becton Dickinson and has served as a consultant to Beckton Dickinson; KK, JH, JMA, DE, DX, and MN declare no competing financial interests. RH, MEW, and DBD report patent applications in the area of closed loop delivery of insulin.

Ethical approval: This study was approved by Cambridge research ethics committee.

Data sharing: The supplemental appendix is available from the corresponding author at rh347@cam.ac.uk.

making may gradually tackle important clinical problems, such as reduction in the duration or severity of hypoglycaemia. As continuous glucose monitors and control algorithms are perfected, devices miniaturised, and performance limiting aspects identified, it is anticipated that early closed loop approaches such as overnight closed loop delivery will be followed by more advanced solutions for control of glucose during both the day and at night. Closed loop systems may serve as a bridge until type 1 diabetes is cured by, for example, stem cell therapy or islet transplantation.

In conclusion, closed loop delivery of insulin can significantly improve the control of glucose levels overnight and reduce the risk of nocturnal hypoglycaemia in adults with type 1 diabetes. The closed loop system has the potential to improve safety and efficacy of insulin delivery and may in future allow more flexible lifestyles in conjunction with improved glycaemic control for people with type 1 diabetes.

We thank Josephine Hayes for administrative support, Angie Watts for laboratory support, Joanna Weston for dietary support, and the staff at Addenbrooke's Wellcome Trust Clinical Research Facility for their help. Steve Luzio and colleagues measured plasma insulin.

Contributors: RH coordinated the studies. MLE, RH, KK, SAA, DBD, SRH, HRM, and MEW co-designed the studies. JH and KK were responsible fo screening and enrolment of participants. KK and JH requested informed consent from the participants. JH, KK, JMA, and DE provided patient care, collected the clinical and laboratory data, and contributed to biochemical analysis. MEW carried out randomisation. MEW, DX, MN, RH, KK, and CK carried out or supported the data analysis, including the statistical analyses. RH designed and implemented the glucose controller. RH, KK, MLE, SAA, SRH, HRM, DBD, and MEW contributed to the interpretation of the results and the writing and critical review of the report. RH had full access to all of the data in the study and takes responsibility for the integrity of the data and the accuracy of the data analysis. Funding: This study was supported by Diabetes UK (BDA07/0003549), Juvenile Diabetes Research Foundation (22-2006-1113, 22-2007-1801, 22-2009-801, and 22-2009-802), Medical Research Council Centre for Obesity and Related metabolic Diseases, and National Institute for Health Research Cambridge Biomedical Research Centre. Smiths Medical supplied the study pumps and Abbott Diabetes Care supplied the Freestyle Navigator devices and sensors for the eating in scenario. Abbott Diabetes Care read the manuscript before submission. No sponsor had any role in the study design, data collection, data analysis, data interpretation, or writing of the report.
1 World Health Organization. Prevention of diabetes mellitus. Report of a WHO study group. WHO, 1994.

2 Shaw JE, Sicree RA, Zimmet PZ. Global estimates of the prevalence of diabetes for 2010 and 2030. Diabetes Res Clin Pract 2010;87:4-14.

3 Onkamo P, Vaananen S, Karvonen M, Tuomilehto J. Worldwide increase in incidence of type 1 diabetes-the analysis of the data on published incidence trends. Diabetologia 1999;42:1395-403.

4 Diabetic Control and Complications Trial Research Group. The effect of intensive treatment of diabetes on the development and progression of long term complications in insulin-dependent diabetes mellitus. N Engl J Med 1993;329:977-86.

5 Amiel S, Beveridge S, Bradley C, Gianfrancesco C, Heller S, James P, et al. Training in flexible, intensive insulin management to enable dietary freedom in people with type 1 diabetes: dose adjustment for normal eating (DAFNE) randomised controlled trial. $B M$ J 2002;325:746-9.

6 Cryer PE. The barrier of hypoglycemia in diabetes. Diabetes 2008;57:3169-76

7 Bode BW, Schwartz S, Stubbs HA, Block JE. Glycemic characteristics in continuously monitored patients with type 1 and type 2 diabetes: normative values. Diabetes Care 2005;28:2361-6.

8 Klonoff DC. Continuous glucose monitoring: roadmap for 21st century diabetes therapy. Diabetes Care 2005;28:1231-9.

9 Tamborlane WV, Beck RW, Bode BW, Buckingham B, Chase HP, Clemons R, et al. Continuous glucose monitoring and intensive treatment of type 1 diabetes. N Engl J Med 2008;359:1464-76

10 Pickup J, Keen $\mathrm{H}$. Continuous subcutaneous insulin infusion at 25 years: evidence base for the expanding use of insulin pump therapy in type 1 diabetes. Diabetes Care 2002;25:593-8.

11 Bergenstal RM, Tamborlane WV, Ahmann A, Buse JB, Dailey G, Davis SN, et al. Effectiveness of sensor-augmented insulin-pump therapy in type 1 diabetes. N Engl J Med 2010;363:311-20.

12 The DCCT Research Group. Epidemiology of severe hypoglycemia in the Diabetes Control and Complications Trial. Am I Med 1991;90:450-9.

13 Cheyne EH, Sherwin RS, Lunt MJ, Cavan DA, Thomas PW, Kerr D. Influence of alcohol on cognitive performance during mild hypoglycaemia; implications for type 1 diabetes. Diabet Med 2004;21:230-7.

14 Hovorka R. Continuous glucose monitoring and closed-loop systems Diabet Med 2006:23:1-12

15 Steil GM, Rebrin K. Closed-loop insulin delivery-what lies between where we are and where we are going? Expert Opin Drug Deliv 2005;2:353-62.

16 Renard E, Costalat G, Chevassus H, Bringer J. Artificial beta-cell: clinical experience toward an implantable closed-loop insulin delivery system. Diabetes Metab 2006;32:497-502.

17 Kowalski AJ. Can we really close the loop and how soon? Accelerating the availability of an artificial pancreas: a roadmap to better diabetes outcomes. Diabetes Technol Ther 2009;11(suppl 1):S113-9.

18 Hovorka R, Allen JM, Elleri D, Chassin LJ, Harris J, Xing D, et al. Manual closed-loop insulin delivery in children and adolescents with type 1 diabetes: a phase 2 randomised crossover trial. Lancet 2010;375:743-51.

19 Bequette BW. A critical assessment of algorithms and challenges in the development of a closed-loop artificial pancreas. Diabetes Technol Ther 2005; 7:28-47. 
20 Hovorka R, Shojaee-Moradie F, Carroll PV, Chassin LJ, Gowrie IJ, Jackson NC, et al. Partitioning glucose distribution/transport, disposal, and endogenous production during IVGTT. Am J Physiol 2002;282:E992-1007.

21 Mazor E, Averbuch A, Bar-Shalom Y, Dayan J. Interacting multiple model methods in target tracking: a survey. IEEE Trans Aerosp Electron Syst 1998;34:103-23.

22 Senice FJ, Molnar GD, Rosevear JW, Ackerman E, Gatewood LC, Taylor WF. Mean amplitude of glycemic excursions, a measure of diabetic instability. Diabetes 1970;19:644-55.

23 Kovatchev BP, Cox DJ, Gonder-Frederick LA, Young-Hyman D, Schlundt D, Clarke W. Assessment of risk for severe hypoglycemia among adults with IDDM: validation of the low blood glucose index. Diabetes Care 1998;21:1870-5.

24 Elleri D, Allen JM, Nodale M, Wilinska ME, Acerini CL, Dunger DB, et al. Suspended insulin infusion during overnight closed-loop glucose control in children and adolescents with type 1 diabetes. Diabet Med 2010;27:480-4.

25 Kovatchev B, Cobelli C, Renard E, Anderson S, Breton M, Patek S, et al. Multinational study of subcutaneous model-predictive closed loop control in type 1 diabetes mellitus: summary of the results. $\int$ Diabetes Sci Technol 2010;4:1374-81.

26 Atlas E, Nimri R, Miller S, Grunberg EA, Phillip M. MD-logic artificial pancreas system: a pilot study in adults with type 1 diabetes. Diabetes Care 2010;33:1072-6.

27 Castle JR, Engle JM, El YJ, Massoud RG, Yuen KC, Kagan R, et al. Novel use of glucagon in a closed-loop system for prevention of hypoglycemia in type 1 diabetes. Diabetes Care 2010;33:1282-7.

28 Turner BC, Jenkins E, Kerr D, Sherwin RS, Cavan DA. The effect of evening alcohol consumption on next-morning glucose control in type 1 diabetes. Diabetes Care 2001;24:1888-93.

29 El-Khatib FH, Russell SJ, Nathan DM, Sutherlin RG, Damiano ER. A bihormonal closed-loop artificial pancreas for type 1 diabetes. Sci Transl Med 2010;2:27ra27.

30 Renard E, Place J, Cantwell M, Chevassus H, Palerm CC. Closed-loop insulin delivery using a subcutaneous glucose sensor and intraperitoneal insulin delivery: feasibility study testing a new model for the artificial pancreas. Diabetes Care 2010;33:121-7.

Accepted: 4 February 2011 